EPJ Web of Conferences 45, 01058 (2013)

DOI: $10.1051 /$ epjconf/20134501058

C) Owned by the authors, published by EDP Sciences, 2013

\title{
Staged the conversion of carbon dioxide in the simulator
}

\author{
R. Lenhard ${ }^{1, a}$, M. Vantúch ${ }^{1}$, and M. Malcho ${ }^{1}$ \\ ${ }^{1}$ University of Žilina, Faculty of Mechanical Engineering, Department of Power Engineering, Univerzitna 1, \\ 01026 Žilina, Slovakia
}

\begin{abstract}
The article described the transmission of low-potential heat measurement carried out on the simulator by using the thermal tube heat exchanger into the Earth. On this Simulator is carried out the research of transmission phenomena at different temperature parameters of temperature and pressure at the inlet to the Simulator and the various parameters of the carbon dioxide, such as the working substances in thermal tube. In the article will be referred to the conclusions arising from experimental measurements on the transmission of low-potential heat and their analysis of the Simulator, as well as the particulars of the theoretical phase of carbon dioxide in thermal tube, depending on the variations in pressure and temperature. While the impact of these two variables will be analyzed for other parameters of the system, such as an input and an output temperature of the coolant in the heat exchanger and the cooling of the surrounding rocks.
\end{abstract}

\section{Transport of the low potential of heat in a laboratory simulator}

Equipment for the use of low-potential geothermal heat without forced circulation of heat carrier in deep well pressure is a power plant that uses domestic energy resources. Such use has a direct impact on the protection of the environment by reducing the production of $\mathrm{CO}_{2}$ in ensuring the thermal wellbeing.

The innovation of the project consists in using lowpotential of the Earth's heat pump carrier heat to flow without the use of a circulating medium deep borehole respectively, of such a model.

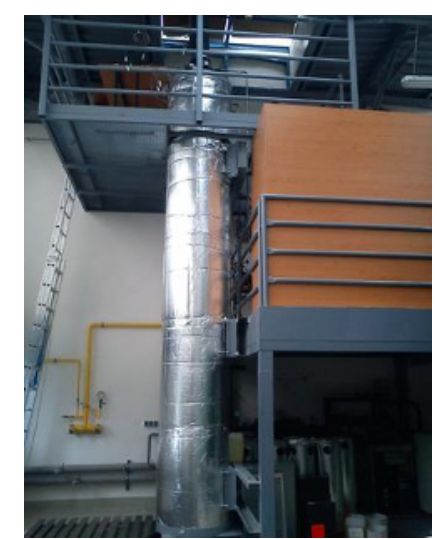

Fig. 1. Overall view of the Simulator.

The purpose designed facility is a simulation of the transport of low-potential heat from rock collector with cooling fluid and thermal tubes in laboratory conditions. It is also possible to perform measurements of heat flows in the same input temperature conditions and at different levels of thermal tubes $\left(\mathrm{CO}_{2}, \mathrm{NH}_{3}\right)$ at various pressures of the tube.

Device (simulator) for the transport of low-potential heat evaporating and condensing part in the transformation phase through the tube at temperatures below $0{ }^{\circ} \mathrm{C}$ enables the development of research activities for the verification of the technology of production of thermal tubes suitable for the use of the Earth's lowpotential heat in a laboratory environment. The individual components of the kinetic parameters of heat transport device allow you to research the Thermo into the heat of the rack on the model of the rock. The device allows for realistic modeling of heat flows from the rocks into the warmth of the carrier medium.

\section{Carbon dioxide as working fill of heat pipes}

As an alternative to the commonly used working media (ethylenglykol) in the tubes of the heat stored in deep boreholes, we selected the carbon dioxide. $\mathrm{CO}_{2}(\mathrm{R} 744)$ is commonly used as the operating fluid in the car air conditioning, food and health care.

The use of $\mathrm{CO}_{2}$ as heat carrier located in thermal tubes in deep boreholes, where, in particular, the application is used as a carrier of heat from the soil to heat exchanger. In the heat exchanger under critical pressure in absorption and the saturated vapor pressure is 4 to 12 times more in comparison with conventionally used refrigeration substances.

arichard.lenhard@fstroj.uniza.sk 


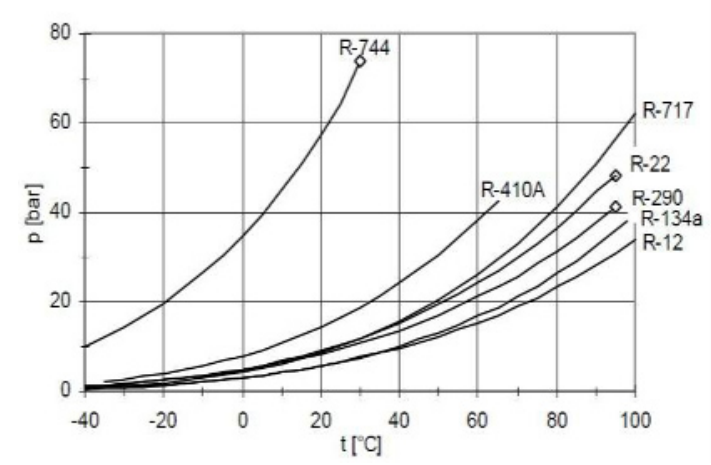

Fig. 2. Characteristics of some cooling media.

From the figure 2 it is obvious that the pressure saturated steam of $\mathrm{CO}_{2}$ is at $0^{\circ} \mathrm{C} 3.5 \mathrm{MPa}$, which is many times more in comparison with other types of cooling substances. The advantage of this medium is also its pressure gradient, which is approximately 1 bar k $^{-1}$. carbon dioxide, which provides heat tube we take out of the cylinder located on the weight. Thus, we can record the quantity $[\mathrm{kg}]$ of $\mathrm{CO}_{2}$ in the heat tubes of the simulator.

In the pressure bottle is a liquid carbon dioxide with ambient temperature. When filling heat pipes in the simulator with gas occurs the decline the temperature of the gas in the influence of evaporation expansion heat which is withdraw. This decrease reflected a significant gas cooling accessory of the pressure bottle. If the supply of gas to quicker we can observe the freezing of accessories.

The difference between the conventional heat transfer materials and $\mathrm{CO}_{2}$ is the fact that in this case phase changes occur changes in condition. Evaporator cooling device in which the $\mathrm{CO}_{2}$ is also a capacitor.

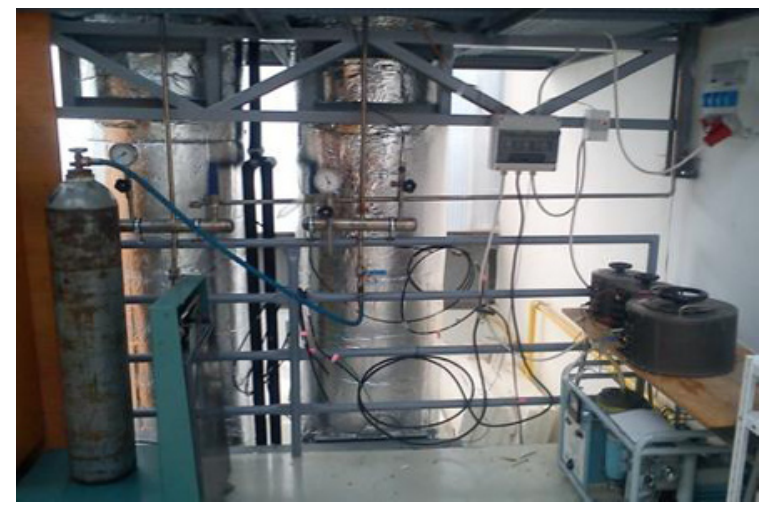

Fig. 3. Performance of thermal tubes placed on the weight of the cylinder of $\mathrm{CO}_{2}$.

In fulfilling empty bottle isothermal process of changing the pressure points of $\mathrm{S}$ figure 4 . At the beginning of the gas in the bottle in the gas phase. After reaching the pressure point of the liquid in the bottle appears. During the next filling is at the same temperature, the pressure in the bottle is constant, but the share of the liquid phase.

If the value of the transactions (in $\mathrm{kg} \mathrm{dm}^{-3}$ or $\mathrm{g} \mathrm{cm}^{-3}$ ) at a given temperature does not exceed the value of the density of the fluid, the pressure will increase and the corresponding curve of saturated steam will correspond to the vapor pressure of the carbon dioxide at a given temperature. However, the value of transactions (in $\mathrm{kg} \mathrm{dm}^{-3}$ or $\mathrm{g} \mathrm{cm}^{-3}$ ) at a given temperature the density exceeds the corresponding curve of saturated liquid, and then in the moment when the value is equal to the density of saturated liquid at a given temperature performance at a given temperature, the gas and liquid phase disappears from the bottle stays only.
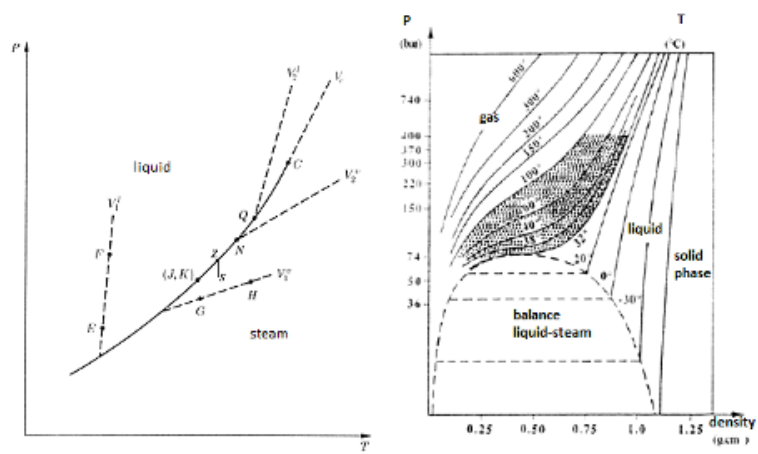

Fig. 4. State behavior of $\mathrm{CO}_{2}$ in the phase diagram.

Changes in the individual conditions of the $\mathrm{CO}_{2}$ (gas phase, liquid phase) can be shown in a state diagrams.

\section{The curve of saturated steam, carbon dioxide}

When evaporation of $\mathrm{CO}_{2}$ in the liquid state in a closed container (heat pipe), is the number of molecules at the beginning of the storyboard, which leave the surface of the liquid $\mathrm{CO}_{2}$ is greater than the number of molecules, which are for the same time returning back into the liquid phase of gas. This process reduces the volume of the liquid phase for the zoom of the current density and vapor pressure above the liquid phase. After some time, where the number of molecules, which occurs the State into liquid phase will be equal to the number of molecules of gas coming back to the stationary phase for the same time they leave.

In such a steady state system, the volume of the liquid and gaseous phase does not change. The steam pressure and the temperature of the system liquid + steam remain constant.

Saturated steam is steam that is in equilibrium with its liquid. The pressure of such steam does not depend on the volume of steam at a constant temperature of, but in raising the temperature, the pressure rises. If the equilibrium system of liquid increases the temperature of saturated steam, so the density rises + the saturated steam and the density of the liquid goes down to the critical temperature.

\section{The phase diagram of carbon dioxide}

The Diagram is composed of 3 curves displayed in one system: the melting-curve, the curve of the phase transformation of the saturation vapor curve $k_{\mathrm{s}}, k_{\mathrm{t}}, k_{\mathrm{p}}$.

All curves have one common point, which we call triple the point. This point represents the equilibrium between solid, liquid and gaseous phases of substance (carbon dioxide). 


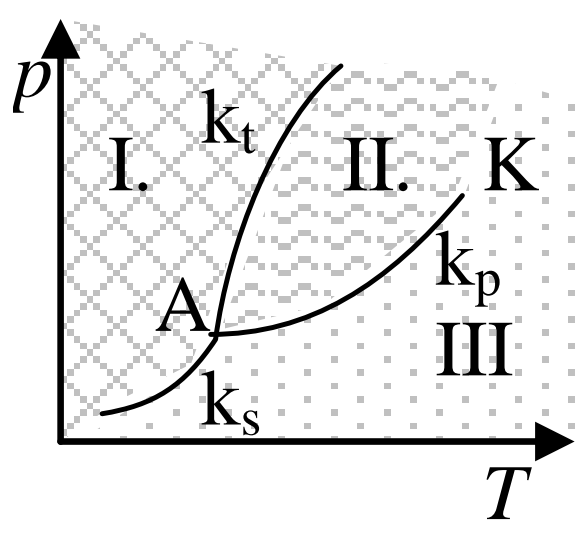

Fig. 5. The phase diagram of carbon dioxide.

These 3 lines divide the chart into 3 areas. Each area surrounding the status of the substance (solid state, I - II. - liquid state, III. - gaseous form-heated steam).

\section{The measurement}

On the Simulator, the transport of low-potential heat measurement has been carried out, which consisted in a gradual and slow pressure heat tubes. By increasing the pressure we are cool to desired temperature corresponding to the depth of $150 \mathrm{~m}$ borehole surroundings under the ground. At an average temperature of $-6.15^{\circ} \mathrm{C}$ heat pipes and corresponding pressure $2.7 \mathrm{MPa}$ started heating model heating cables using borehole. el. during the 36 hours. We maintain a constant average temperature and $\mathrm{CO}_{2}$ pressure record. We have reached a State of equilibrium, in which carbon dioxide saturation curve is on. In that State there is a change of State of $\mathrm{CO}_{2}$ gas to liquid and heat exchange surfaces of the heat transfer process works on the heat exchanger tubes in heat.

- Volume 4 heat pipes in the simulator: $V_{\mathrm{tt}}=49 \mathrm{~m} \mathrm{l}$ (of which 4 in the heat exchanger the heat tubes introduced volume: $V_{\mathrm{tv}}=71$ ).

- Volume of the heat exchanger: $V_{\mathrm{vt}}=211$.

- Volume of coolant in the heat exchanger:

$V_{\text {ch.kvap }}=13.81$.

- Heat exchange surfaces of the heat exchanger tubes in heat Content: $S_{\mathrm{tt}}=0.19 \mathrm{~m}^{2}$.

- The initial state of the Simulator was the following:

$P_{0}=1.516 \mathrm{MPa}, m \mathrm{co}_{2}=1.5 \mathrm{~kg}$.

- Average temperature $T_{0}=19.23{ }^{\circ} \mathrm{C}$.

$$
\begin{gathered}
P_{0} V_{\mathrm{tt}}=m_{0} r T \\
m_{0}=\left(P_{0} V_{\mathrm{tt}}\right) /(r T) \\
m_{0}=(1.516 \times 0.049) /(188.95 \times 290.25) \\
m_{0}=1.35 \mathrm{~kg}
\end{gathered}
$$

- $\mathrm{CO}_{2}$ gas constant: $188.95 \mathrm{~J} \mathrm{~kg}^{-1} \mathrm{~K}^{-1}$.

- Average temperature in the simulator: $T=292.35 \mathrm{~K}$.

Heat the tube to further fulfill $\mathrm{CO}_{2}$ from the initial weight of the filled bottle was $84.3 \mathrm{~kg}\left(30 \mathrm{~kg}\right.$ of $\left.\mathrm{CO}_{2}\right)$. The total mass of $\mathrm{CO}_{2}$ in the heating tubes was: $m_{1}=5.8 \mathrm{~kg}$. JULABO cooling thermostat was set to $-15^{\circ} \mathrm{C}$, which is the power of $850 \mathrm{~W}$.
Stable flow rate during measurement: $\dot{m}=11 \mathrm{~kg} \mathrm{~min}^{-1}$. Difference between input and output temperature of the heat exchanger during the 36 hours $\Delta t=0.34{ }^{\circ} \mathrm{C}$.

- Heat capacity Thermal G: $c=3.33 \mathrm{~J} \mathrm{~kg}^{-1} \mathrm{~K}^{-1}$.

- 36 hour record of steady-state average temperature: at the beginning of the record: $t_{1}=-6.15^{\circ} \mathrm{C}$ average temperature, after 36 hours, $t_{2}=-6.39^{\circ} \mathrm{C}$.

- The pressure at the start of 36 hours, $P_{1}=$ pressure at the end of the 36 hour $2.708 \mathrm{MPa}$, record: $P_{2}=2.68 \mathrm{MPa}$.

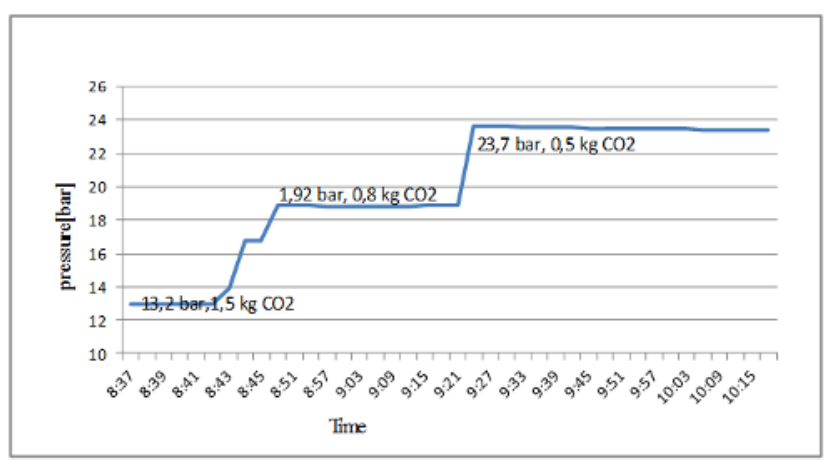

Fig. 6. The gradual increase of pressure in the heat tubes.

A total of 5 times from 0 to $3.4 \mathrm{MPa} \mathrm{MPa}$ filled. The total amount of $\mathrm{CO}_{2}$ in the tubes $=5.8 \mathrm{~kg}$ of $\mathrm{CO}_{2}$.

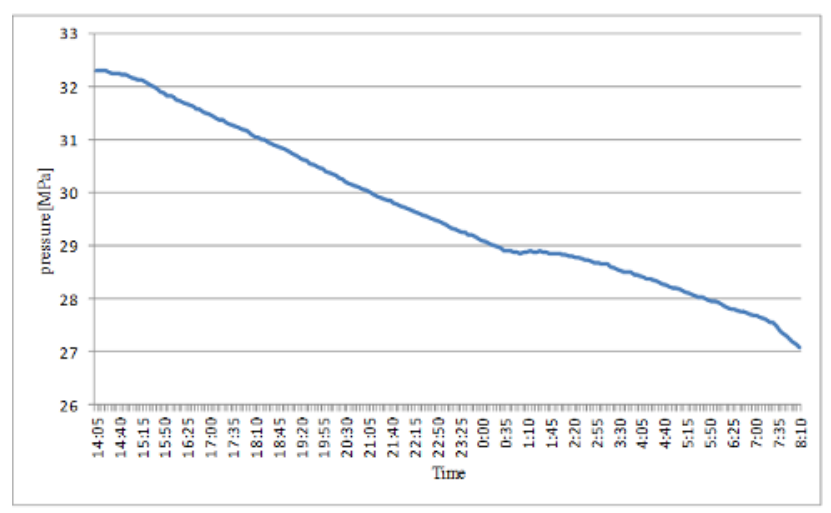

Fig. 7. The gradual increase of pressure in the heat tubes.

From measurements that are carried out on the Simulator shows that increasing the $\mathrm{CO}_{2}$ pressure in heat pipes results in decrease of temperatures throughout the height and diameter of a borehole.

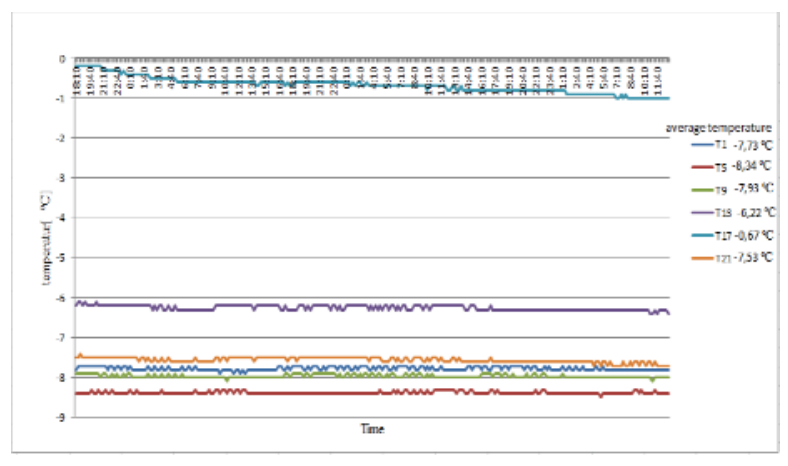

Fig. 8. Course of temperatures (62 hours).

The total mass of $\mathrm{CO}_{2}$ in the simulator $=5.8 \mathrm{~kg}(11 \%$ of the volume of heat pipes). 
Liquid phase:

$$
\begin{gathered}
m_{\mathrm{k}}=\rho_{\mathrm{l}} \times V_{\mathrm{tt}} \\
m_{\mathrm{k}}=1101.1 \mathrm{~kg} \mathrm{~m}^{-3} \times 0.049 \mathrm{~m}^{3} \\
m_{\mathrm{k}}=54 \mathrm{~kg} \text { liquid } \mathrm{CO}_{2}(20 \%=8 \mathrm{~kg}) \\
\text { The gas phase }: \\
m_{\mathrm{p}}=\rho_{\mathrm{g}} \times V \mathrm{tt} \\
m_{\mathrm{p}}=1.85 \mathrm{~kg} \mathrm{~m}^{-3} \times 0.049 \mathrm{~m}^{3} \\
m_{\mathrm{p}}=0.0906 \mathrm{~kg}
\end{gathered}
$$

- 36 h. record.

- The average entry temperature $-10.397^{\circ} \mathrm{C}$.

- Average temperature $-10.057^{\circ} \mathrm{C}$.

$-\Delta t=-0.34{ }^{\circ} \mathrm{C}$.

- Average $t$ in the simulator at the beginning $-6.15^{\circ} \mathrm{C}$.

- Average $t$ at the end $-6.39{ }^{\circ} \mathrm{C}$.

- AC power $P=35 \mathrm{~W}$.

\section{Conclusion}

In laboratory conditions, it is possible by changing the pressure and temperature and carbon dioxide $\mathrm{CO}_{2}$ to reach saturation point. If we can keep this status and at the same time accumulate heat into a borehole heat exchanger to ensure long-term collection we know. In real terms, however, it is not possible during the annual period. Carbon dioxide as the working substance in heat tubes working without the forced circulation has the potential to be used in real operations.

\section{Acknowledgement}

Article has been worked out in the framework of the operational programme research and development-ITMS26220220057 "Device for the use of low-potential geothermal heat without forced circulation of heat carrier in deep well pressure".

\section{References}

1. D. Petráš, Nízkoteplotné vykurovanie a obnovitel’né zdroje energie, 216 (2009)

2. L. Čápla, B. Koutský, P. Buryan, Technická zpráva č. 10/04 Studie závislosti tlaku oxidu uhličitého na teplotě, Praha, (2004)

3. R. Lenhard, M. Malcho, Elsevier-An International Journal Mathematical and Computer Modelling 57, 111-125, (2013)

4. J. Jandačka, Š. Papučík, V. Dekýšs, R. Melicher, Communications 10, 40-44, (Scientific Letters of the University of Žilina, 2008)

5. Š. Papučík, P. Pilát, K. Kaduchová, IN-TECH, 117119, (2011)

6. R. Nosek, J. Jurkechová, Š. Papučík, J. Jandačka, Exp. Fluid Mech. (2010)

7. J. Müllerová, Štýl pre váš interiér a exteriér 2, 18-19 (2002)

8. M. Jakubský, R. Lenhard, M. Vantuch, Energetika a životní prostředi 40, (2010)
9. R. Lenhard, J. Jandačka, M. Jakubský, Aplikácia experimentálnych a numerických metód v mechanike tekutín 17, 185-189, (2010)

10. S. Gavlas, Produktivita a inovácie 12, 21-23 (2011)

)

